This item was submitted to Loughborough's Research Repository by the author.

Items in Figshare are protected by copyright, with all rights reserved, unless otherwise indicated.

\title{
Turbo-discharging turbocharged internal combustion engines
}

PLEASE CITE THE PUBLISHED VERSION

http://dx.doi.org/10.1177/0954407012455986

PUBLISHER

(c) Sage

VERSION

AM (Accepted Manuscript)

LICENCE

CC BY-NC-ND 4.0

REPOSITORY RECORD

Williams, Andrew M., Alan T. Baker, Colin P. Garner, and Ramkumar Vijayakumar. 2019. "Turbo-discharging Turbocharged Internal Combustion Engines”. figshare. https://hdl.handle.net/2134/13306. 
This item was submitted to Loughborough's Institutional Repository (https://dspace.lboro.ac.uk/) by the author and is made available under the following Creative Commons Licence conditions.

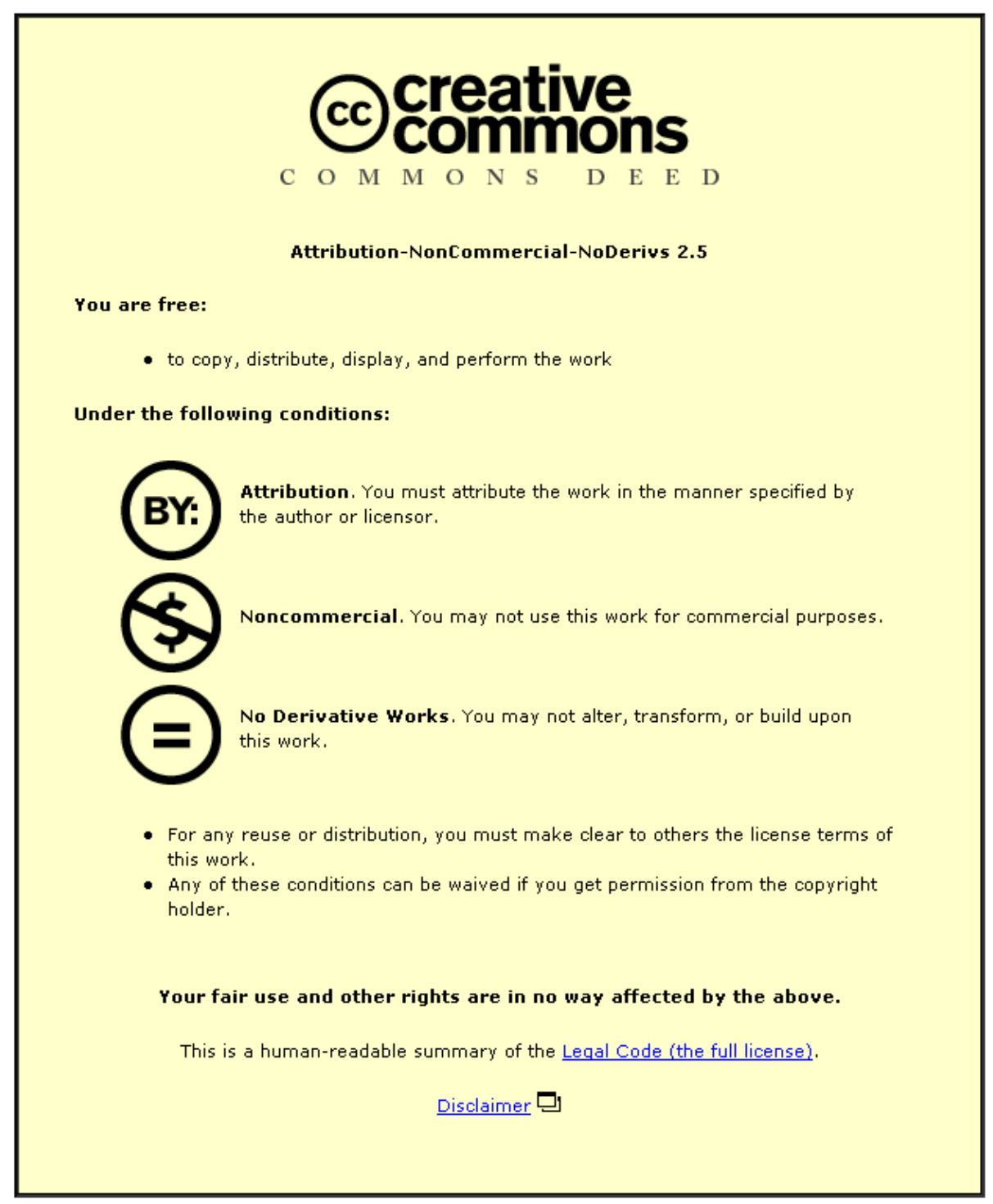

For the full text of this licence, please go to: http://creativecommons.org/licenses/by-nc-nd/2.5/ 


\title{
Turbo-Discharging Turbocharged Internal Combustion Engines
}

\author{
A.M. Williams, A.T. Baker, C.P. Garner and R. Vijayakumar \\ Wolfson School of Mechanical and Manufacturing Engineering \\ Loughborough University, Leicestershire LE11 3TU, UK
}

\section{$\underline{\text { Abstract }}$}

Turbo-discharging is a novel approach that can better utilise the energy recoverable by a turbine (or series of turbines) mounted in the exhaust flow of internal combustion (IC) engines. The recovery of blowdown pulse energy in isolation of displacement pulse energy allows the discharging (depressurisation) of the exhaust system to reduce engine pumping work and improve engine fuel economy. This is a novel approach to air system optimisation that has previously been studied for naturally aspirated engines. However, to be successful, turbo-discharging should be applicable to turbocharged engines as downsizing is a promising direction for future powertrain systems.

This study uses one-dimensional gas dynamics modelling to explore the effect of turbodischarging on a turbocharged gasoline engine, particularly focusing on the interaction with the turbocharging system. The results show that the peak engine torque is increased at low to mid speeds with high speed torque slightly reduced due to restrictions in engine breathing with low lift exhaust valves. The engine peak torque as a function of speed with a larger turbocharger with turbo-discharging was comparable 
to that of the smaller turbocharger without turbo-discharging. Fuel economy improvements were evident over most part load regions of the engine map with peak values varying from 2 to $>7 \%$ depending on the baseline engine air system strategy. Hot trapped residual mass was consistently reduced across a large fraction of the engine map with the exception of high power conditions where the valve pressure drop effect dominated.

The results from this study are promising and show that the use of some of the available exhaust gas energy for turbo-discharging in preference to turbocharging can have a positive effect on both part load and full load engine performance. There remains significant potential for further optimisation with application of variable valve actuation and turbocharger control systems (e.g. variable geometry turbines and waste-gating).

\section{Introduction}

Internal combustion (IC) engines are used widely due to their high power density, low cost, robustness and their ability to run on a variety of high energy density fuels derived from multiple sources ${ }^{[1]}$. Significant deviations from the use of IC engines as the prime energy conversion technologies for transportation, machinery and power generation such as full electric vehicles and fuel cells do not yet offer all of these advantages. Therefore, IC engines are widely accepted to be an integral part of the international energy system for the foreseeable future ${ }^{[2]}$. Increased powertrain electrification will enable significant energy flow optimisation, however, the conversion of liquid fuels to 
mechanical work still has significant potential for energy conversion efficiency improvements in support of wider efforts to reduce impact on resource depletion and climate change. Indeed, the industry is responding with advancements in a number of ways including control strategies; reduction of ancillary demand; parasitic losses; waste energy recovery and thermodynamic improvements ${ }^{[3][4][5][6]}$. This paper describes the latest research into turbo-discharging, a novel air system technology that, as far as the authors are aware, is a unique approach to achieving fundamental thermodynamic improvements to IC engine operation.

The interaction of engine air systems (both intake and exhaust gas pathways) with the thermodynamic performance of the engine and the overall thermal efficiency is multifaceted. The intake air system is considered here to include the air filtration system, the turbocharging system, the cooled exhaust gas recirculation system (if applicable) and the intake valves. The exhaust gas system is considered here to include the exhaust valves, turbocharging system, aftertreatment system and flow tuning and noise control systems. The engine's air system has a significant impact on the peak engine torque and power, the cycle temperatures (and therefore emissions), and the thermal efficiency of the engine. A turbine mounted in the exhaust flow recovers energy from the exhaust gas that is passing through it, however, it is important to recognise that only a fraction of the energy available to the turbine can be considered 'normally wasted' energy. Figure 1 shows the idealised thermodynamic properties on a pressurevolume diagram. Area (a) shows the normally wasted energy that is in the exhaust gas at end of expansion. The presence of the turbine typically results in a higher manifold 
pressure than if it were not present which leads to increased pumping work shown as area (b). Smaller turbines have increased pumping work compared to larger turbines and therefore larger turbines are preferred where transient response and low speed torque targets can still be achieved. The increased pumping work manifests itself as additional work available to the turbine that would not have normally been wasted. For this reason, turbines that maximise energy recovery during the blowdown pulse while minimising cylinder pressure during the displacement pulse offer fundamental improvements in the thermodynamic cost of the energy extraction. In practice, this effect can be seen with the use of larger turbines at high engine speeds in preference to smaller turbines (or the use of variable geometry turbines, VGTs) for fuel economy. Some systems work towards this optimum by physically isolating the blowdown pulse from the displacement pulse e.g. turbo-discharging ${ }^{[7]}$ and Divided Exhaust Period $(\mathrm{DEP})^{[8]}$.

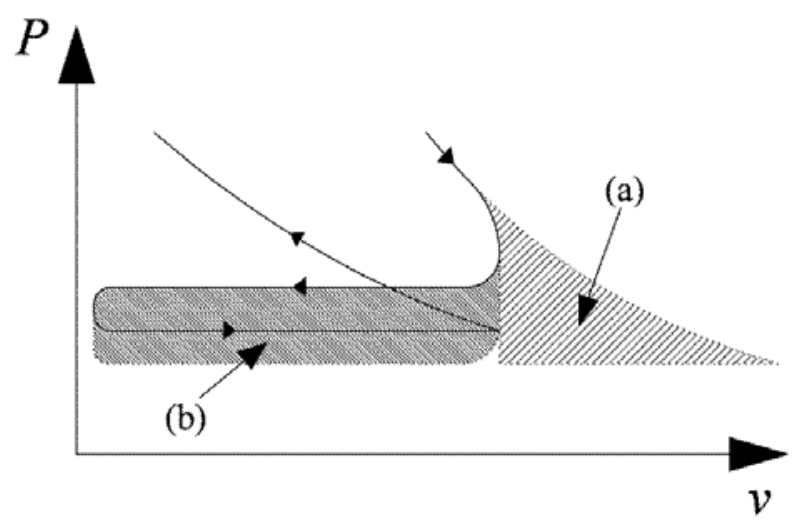

Figure 1. Idealised P-v diagram showing (a) 'normally wasted' energy recoverable by a turbine and (b) additional crankshaft work available to the turbine 
Energy extracted from exhaust gases using turbines is often used to compress the intake charge and, therefore, allow more fuel to be burnt i.e. turbocharging. This enabled increased engine power density with comparatively small additional cost and bill of materials. For this reason turbocharging technology is now dominant in the transport diesel engine market. A more recent trend for throttled gasoline engines is that of downsizing. The increased engine specific torque allows a smaller engine to be used for the same application meaning that for a given torque demand, there is less throttling and consequently reduced pumping losses and improved engine efficiency. The fuel economy benefits are reported to be $>15 \%$ and is therefore a likely technology direction for future gasoline engines.

Much incremental development of turbocharger technology is evident with advancement in material properties and manufacturing processes allowing higher temperature turbine and compressor operation ${ }^{[9]}$ reducing the need for overfuelling to reduce turbine inlet temperatures at high engine power conditions and increasing durability of multiple boost systems. Optimisation of turbocharger geometry for engine condition lends itself well to the use of variable geometry turbines with next generation systems considering high speed optimisation ${ }^{[10]}$ to maximise performance. Such developments are important to continue to advance whole powertrain system efficiencies. The general direction of the energy flow through the air system continues to be from the exhaust to the intake with some efforts to move energy from the exhaust system to the drivetrain (i.e. turbocompounding). This paper considers more fundamentally the energy flows and interactions in the air system with a third energy 
flow path - to the exhaust system. The options for how to use the exhaust energy recovered through a turbine can therefore be categorised as:

1. Turbocharging: use of turbine extracted energy to pressurise the intake charge

2. Turbocompounding: use of turbine extracted energy to contribute directly to crankshaft work

3. Turbo-discharging: use of turbine extracted energy to depressurise the exhaust manifold $^{[7]}$

Figure 2 shows diagrammatically the fundamental air flow pathways for these categories in relation to the engine cylinders. The fuel economy benefits of turbocharged gasoline engines by downsizing $(>15 \%)$ is significantly higher than the expected benefits from either turbocompounding or turbo-discharging $(\sim 4 \%)$ used in isolation. Therefore, prevalence of turbo-charged IC engines is likely to increase in the near future. Both turbocompounding and turbo-discharging, however, offer benefits at part load that if used in conjunction with charging systems have the potential to deliver noticeable improvements to vehicle drive cycle fuel economy. Turbo-discharging in particular has a much shorter history and the full potential of this technology is yet to be defined. Its interaction with turbocharging systems and turbo-compounding systems is complex, however, turbo-discharging has been shown to offer some potentially significant benefits including:

1. reduced pumping work and therefore improved fuel economy; 
2. relatively small effect on the combustion system, therefore existing calibration methods are still valid;

3. reduced in-cylinder trapped residual fraction leading to extended knock boundary and, therefore, potential for combustion advance and/or compression ratio increase ultimately leading to fuel economy and performance improvements;

4. it is widely applicable, i.e. to any engine architecture with a blowdown pulse;

5. it requires no significant changes to core engine architecture.
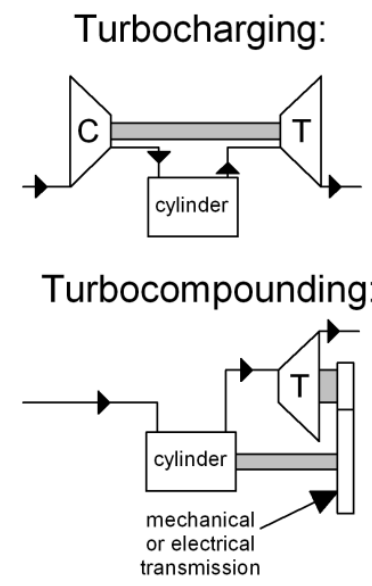

Turbo-discharging:

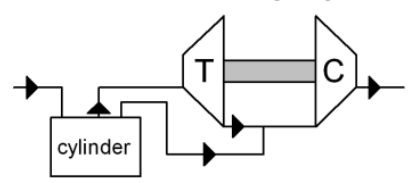

Figure 2. Schematic of air flow pathways for turbocharging, turbocompounding and turbo-discharging systems in isolation 
Turbo-discharging has been previously investigated in detail in the context of naturally aspirated gasoline engines ${ }^{[7]}$. With most current interest in turbocharged engines it is important to evaluate the potential of turbo-discharging in the context of turbocharged engine architecture. Figure 3 shows a schematic of the turbo-discharged system applied to a turbocharged gasoline engine. The system utilises two exhaust ports. One is routed through the turbo-discharging turbine whilst the other by-passes it. With appropriate valve timings, this allows the temporal separation of the blowdown pulse flow and the displacement pulse flow. The turbo-charging system however, requires maximum energy recovery to achieve the required peak engine torque and, therefore, is exposed to the entire exhaust flow. The energy extracted from the turbo-discharging turbine is then routed to a pump located downstream in the exhaust flow path leading to a depressurisation of the exhaust system and either an increased expansion ratio across the turbocharging turbine, or a lower manifold pressure leading to reduced pumping work and hot trapped in-cylinder residual fraction. The potentially increased turbine pressure ratio is beneficial for higher engine torques and improved engine breathing for part load operation. In addition, the potential for reduced in-cylinder hot residuals may allow spark timing to be advanced, compression ratio increased or reduce the required quantity of cooled exhaust gas recirculation (EGR). Each of these potential interactions is of significant current interest. 


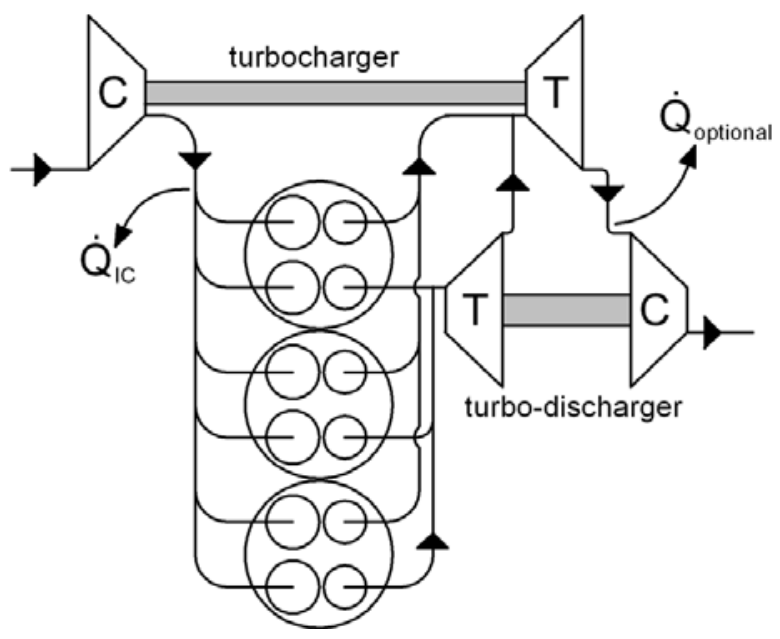

Figure 3. Schematic of a turbo-discharged turbocharged IC engine air system. $Q_{I C}$ is the heat removed by the intercooler and $\mathrm{Q}_{\text {optional }}$ is the heat rejected from the exhaust system.

Turbo-discharging uses energy to improve engine breathing and improve pumping work. Turbo-charging has a similar effect on pumping work, however, can achieve significantly higher engine torques due to the increased charge air density. The optimum energy split between the intake and exhaust is not clear and is explored in this paper. The benefits of turbo-discharging are more apparent in under conditions where the energy would otherwise not contribute to improving engine pumping work. For example, part load throttled SI engine conditions (with turbocharging) would observe an increased exhaust back pressure due to the turbine energy recovered without the associated increase in intake manifold pressure due to the throttle based load control. It will, therefore, be more efficient to use the available energy in the exhaust system where it can contribute to improvements in pumping work and engine 
breathing. Likewise, at very high levels of single stage boost, a unit of energy recovered from the turbine will have a smaller benefit to pumping work on the intake side when compared to the exhaust side due to the higher stage pressure ratio. Therefore, at mid to high loads, some benefit is expected from a combination of turbocharging and turbo-discharging. With this in mind, two markets stand out for which turbo-discharging would be of most benefit:

1. Passenger car throttled gasoline engines, specifically at part load operation where available exhaust gas energy cannot readily be used for improving pumping work through the turbocharging system.

2. Power generation, where the value of incremental fuel economy benefits at part, mid and high loads is high.

This paper focuses on the application of turbo-discharging to highly turbocharged passenger car gasoline engines to explore, for the first time, the interaction between the turbo- systems and to quantify the potential benefit. One-dimensional gas dynamic simulations in Ricardo WAVE have been used unconstrained by present combustion limitations to fully explore the effects of turbo-discharging future turbocharged engines.

\section{Simulation Method}

A 1-D gas dynamics simulation of a naturally aspirated (NA) 1.39 litre gasoline engine has previously been used in Ricardo WAVE to study characteristics of an isolated turbo-discharging system ${ }^{[7]}$. This model represents an engine installed at 
Loughborough University allowing experimental validation and demonstration of turbodischarging on a NA engine. This base model has been modified with a reduced compression ratio and single stage turbocharging system with the engine specification shown in Table 1. The simulations presented here retain the standard valve diameters to avoid significantly increasing thermal stresses in this region of the engine assembly. This does reduce performance and is an area for potential further improvement.

\begin{tabular}{|l|c|}
\hline \multicolumn{2}{|c|}{ Table 1. Engine Specification } \\
\hline Total swept volume & 1.39 litres \\
\hline Bore & $76.0 \mathrm{~mm}$ \\
\hline Stroke & $76.5 \mathrm{~mm}$ \\
\hline Connecting rod length & $136.3 \mathrm{~mm}$ \\
\hline Number of cylinders & 4 \\
\hline Valves per cylinder & 4 \\
\hline Exhaust valve diameter & $24.1 \mathrm{~mm}$ \\
\hline Intake valve diameter & $28.1 \mathrm{~mm}$ \\
\hline Compression ratio & $9.2: 1$ \\
\hline Model fuel & Indolene \\
\hline
\end{tabular}

To explore the effect of the turbo-discharging system on the turbocharging system, cam profiles, valve timings and combustion characteristics were fixed as speed and engine load was varied. The combustion model was based on a single homogeneous zone with heat release and gas properties as a function of a pre-defined burn rate with a 50\% mass fraction burn point of 8 degrees crank angle after top dead centre and a $10-90 \%$ burn duration of 20 degrees crank angle. The air-fuel ratio was fixed at stoichiometric conditions to maintain exhaust gas properties appropriate for 3-way catalysts. 
The valve flow coefficients on the NA engine were measured on a Superflow SF600E steady flow test rig across the range of typical valve lifts. The optimisation of valve timings for the temporally split high and low pressure manifold valve events requires shorter valve durations and (for a cam driven system) a lower valve lift. A study of realistic cam profiles was undertaken for a range of valve durations considering geometrical limitations and an acceleration limit of 1.6 times the NA engine base design. The relationship between valve lift and valve opening duration is shown in Figure 4.

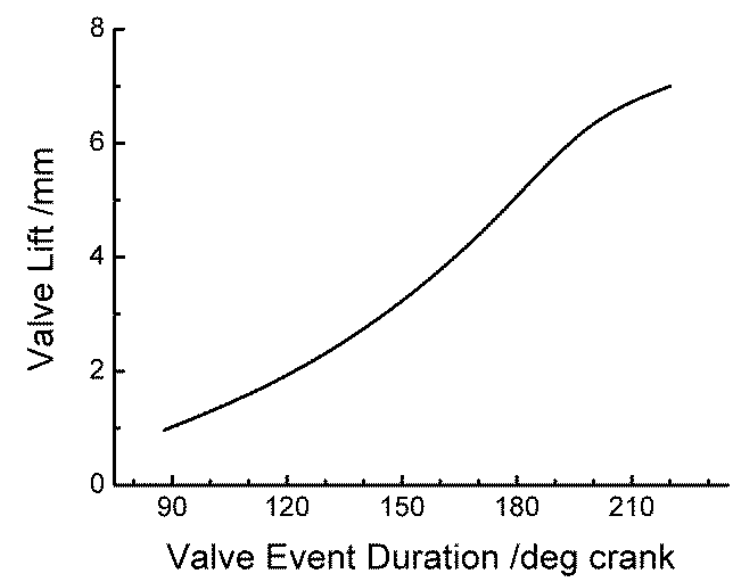

Figure 4. Relationship between valve event duration and maximum lift

The turbocharger and turbo-discharger were simulated using mapless flow elements in Ricardo WAVE with specified effective nozzle diameters for the turbine. Effective nozzle diameters for the turbocharger were chosen to behave similarly to the torque curve for the large and small turbochargers investigated in [11] in which no high-load 
EGR was used. The heat exchangers were modelled as multiple tubes with fixed wall temperature. The charge air cooler cooled the intake flow to $50^{\circ} \mathrm{C}$ and an exhaust heat exchanger upstream of the turbo-discharger pump cooled the gas to typically $130^{\circ} \mathrm{C}$. The exhaust system included a wall conduction model to determine exhaust flow heat transfer and exhaust wall temperatures. It consisted of a $1.6 \mathrm{~mm}$ thick stainless steel single wall with natural convection to a $300^{\circ} \mathrm{C}$ ambient environment.

The valve timings were optimised for 8 bar BMEP operation by comparison of simulations with $70 \%, 80 \%, 90 \%$ and $100 \%$ of the standard engine valve event durations. The valve lift was scaled as shown in Figure 4. The low pressure valve closing was set to 5 degrees crank after the intake valve opening and the high pressure valve opening was varied in 10 degree crank intervals. Further optimisation potential exists with the valve overlap period particularly with VVA systems which will allow variation as a function of engine speed and load. The simulation results shown are based on fixed valve timings across the entire speed and load range, shown in Figure 5 for the low lift valve events. The intake valve timing and profile was constant throughout all simulations to ensure the predicted effect on engine fuel economy was due to the exhaust system and the turbocharging system only. 


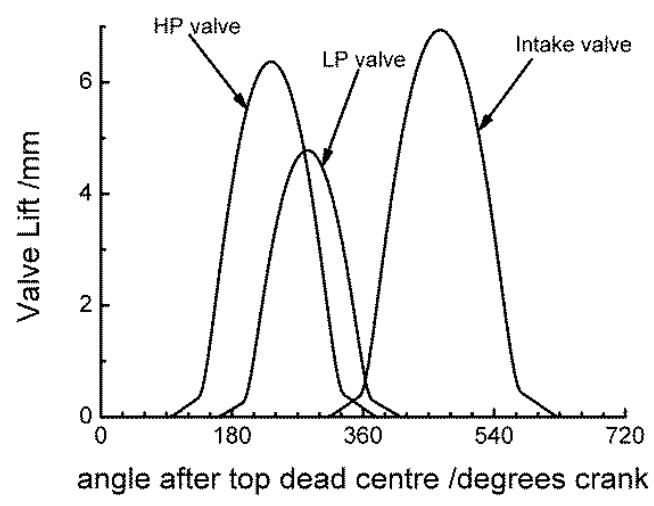

Figure 5. Example low lift valve timings used for simulations

\section{System Characteristics}

Figures 6 and 7 show cylinder and manifold pressures for a part load (8 bar BMEP) and peak load case respectively at $2000 \mathrm{rpm}$. These plots show the blowdown pulse recovery through the high pressure manifold and turbine. For the part load case, the turbocharging turbine has been intentionally bypassed as turbocharging under these conditions contributes negatively to engine losses (i.e. pumping work). Figure 6 is comparable to previous work on NA engines ${ }^{[7]}$ whereas Figure 7 shows effects unique to turbocharged engines. At high load, the blowdown energy pulse can be seen to be effectively routed through the turbo-discharging turbine while retaining a significant pressure drop across the turbocharging turbine. This is required to achieve required boost levels. In the peak load case shown, the energy split is such that the turbocharger turbine outlet pressure is $\sim 0.7$ bar (absolute) leading to $>30 \%$ increase in 
pressure ratio for a given upstream pressure when compared to the conventional engine.

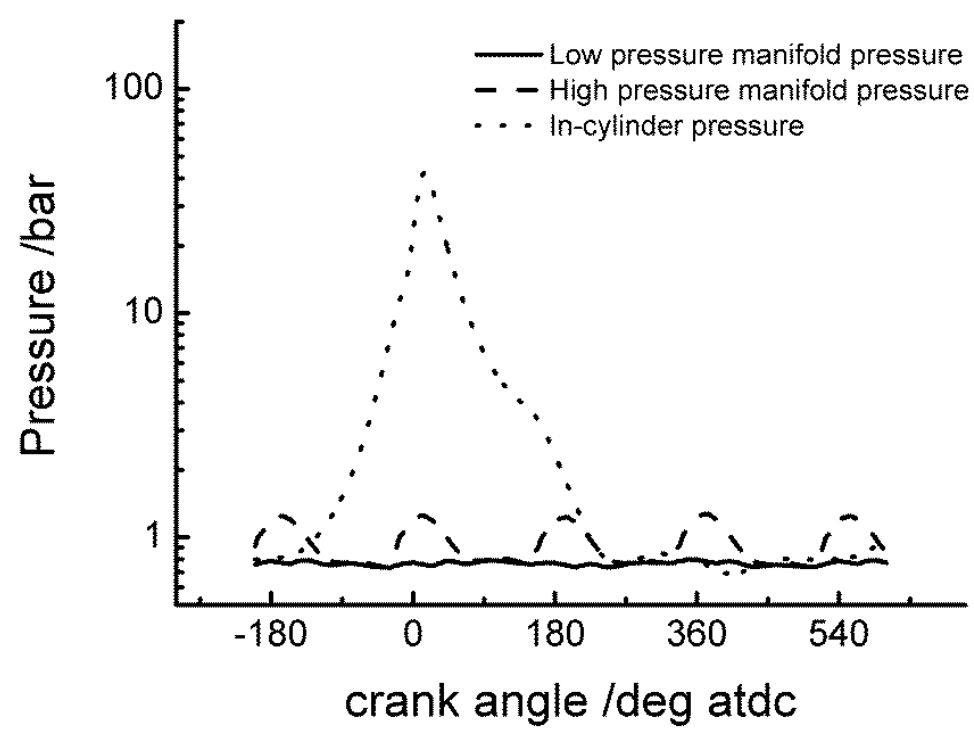

Figure 6 Cylinder pressure and exhaust manifold pressures for part load operation (8 bar BMEP, 2000 rpm) 


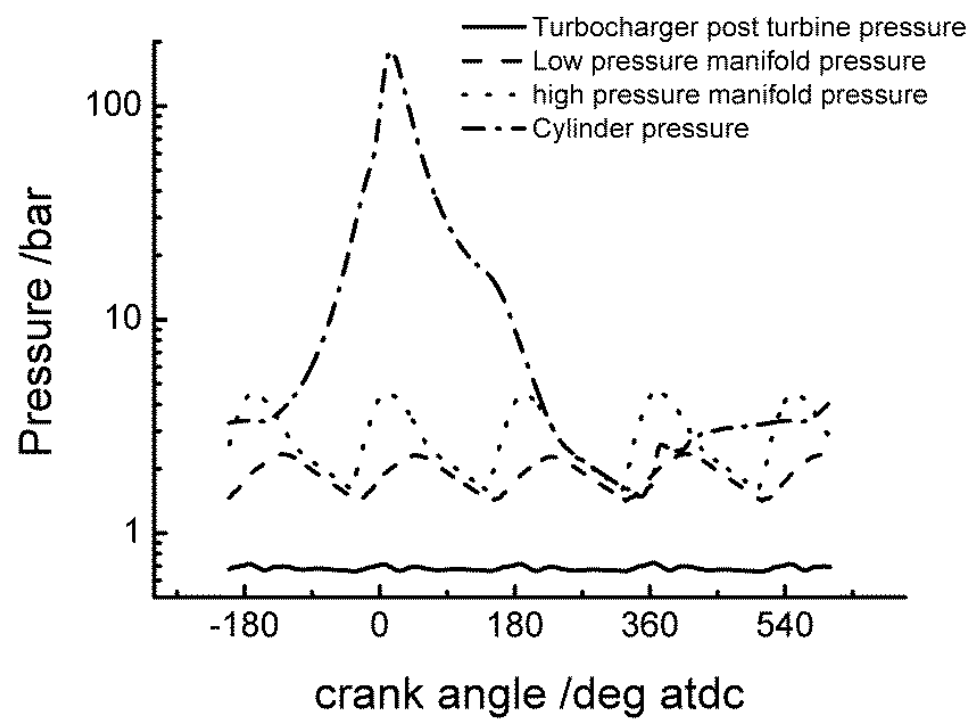

Figure 7 Cylinder pressure, exhaust manifold pressures and post turbocharger turbine pressure for full load operation (2000 rpm)

The mass flux through each valve is shown for the low valve lift conditions in Figure 8. The mass flux during the blowdown pulse is significantly higher than that during the displacement pulse for both part load and high load operation. At very low loads, the blowdown pulse can reduced to negligible levels and even be reversed due to the degree of throttling. 


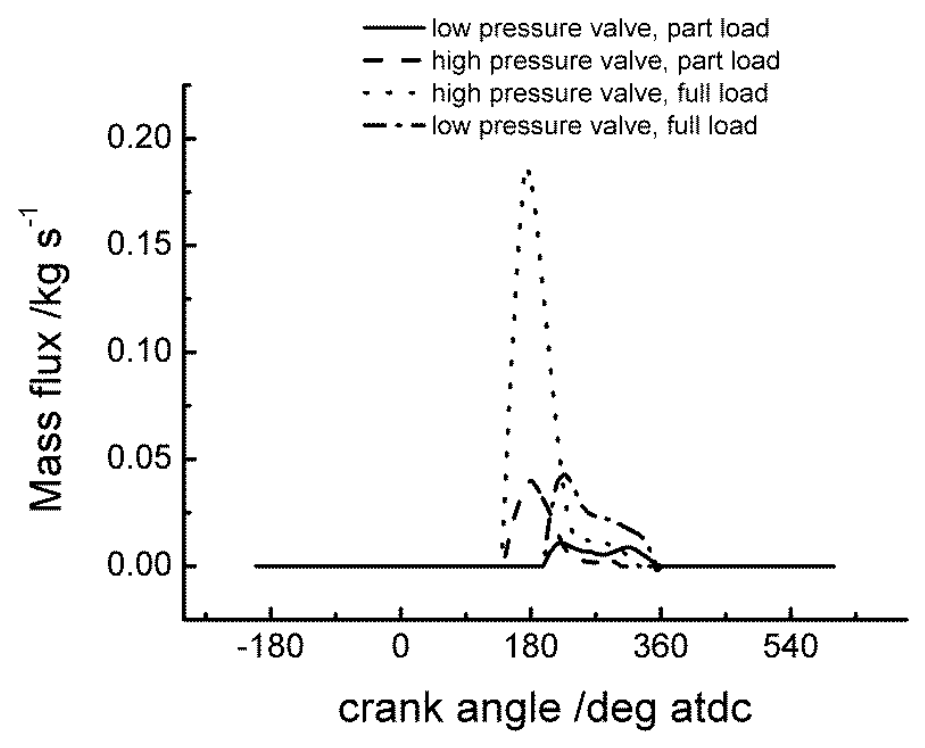

Figure 8 Instantaneous mass flux into the exhaust manifolds from cylinder 1 for part load and full load operation (2000 rpm)

The most important control approach for determining the air system behaviour is the energy split between the two turbines. At part load, additional energy to the boost system results in increased exhaust system back pressure for little gain in pumping work due to the throttle based load control. Under such low/no boost conditions the optimum energy split is to have maximum energy flow to the exhaust system. In practice, this could be achieved by bypassing the turbine or varying its geometry to reduce the turbocharger turbine pressure drop (VGTs).

At full load conditions the engine power is primarily determined by the amount of air available to oxidise the fuel and therefore a function of the boost pressure. As turbo- 
discharging reduces pumping work, in isolation it is fundamentally limited to an MEP benefit of less than the standard engine exhaust system absolute pressure and is therefore not capable of achieving required engine power densities without combination with a boost system. For this reason it is expected that most of the available energy will need to be used for turbocharging enabled by waste-gating, variable geometry turbodischarger or variable valve actuation (particularly timing). Turbo-discharging reduces the upstream pressure and temperature of the turbocharging turbine (acting to reduce the boost pressure) while reducing the turbine outlet pressure (acting to increase the boost pressure). Simulations of the effect of turbo-discharger size and valve profiles were used to explore this effect. The valve event shown in Figure 5 is referred to as the low lift valves whereas the standard engine valve event refers to a more conventional cam profile and timing.

Figure 9 shows the peak engine torque for three cases when the smaller turbocharger was used, targeting low speed torque. The effect of turbo-discharging with low valve lifts was to marginally increase low speed engine torque at $2000 \mathrm{rpm}$ crossing over around 3000 rpm before reducing engine torque at higher speeds, by $\sim 11 \%$ at 5000 rpm. With the larger turbocharger, shown in Figure 10, the same effect can be observed; however, the increase at $2000 \mathrm{rpm}$ is significantly more prominent with $65 \%$ increased engine torque. In both cases, the switching of the exhaust valves to a more conventional lift profile reduces the impact of turbo-discharging to levels that result in typically less than $5 \%$ torque detriment at high engine speeds. 


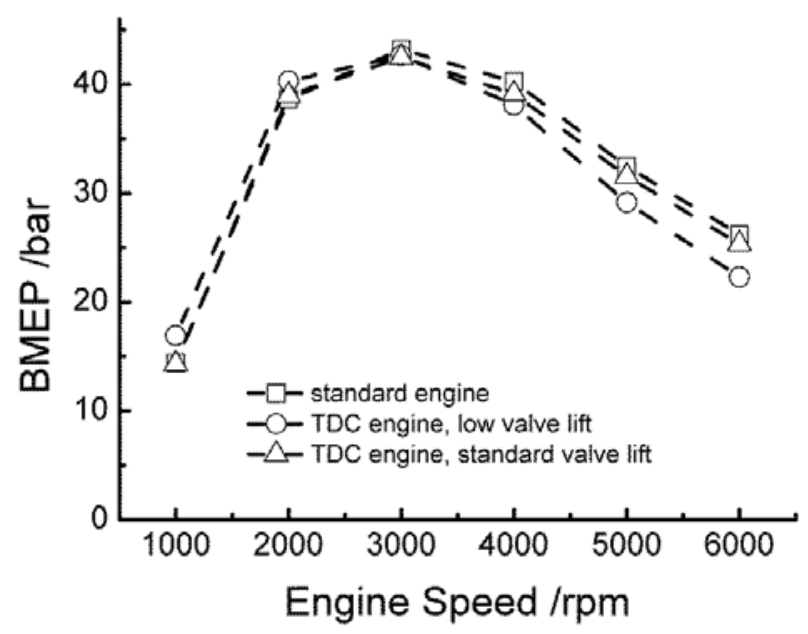

Figure 9 Engine torque curve for baseline and turbo-discharged engines using a small turbocharger

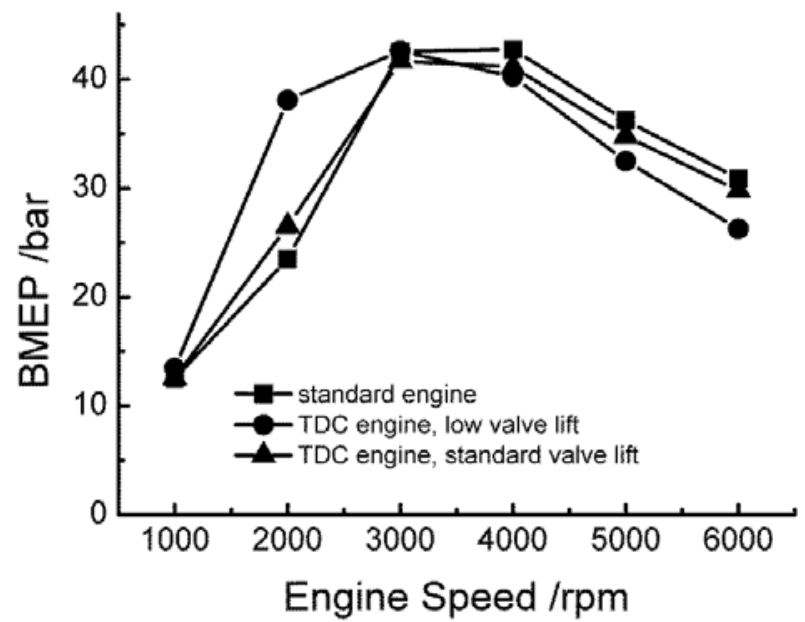

Figure 10 Engine torque curve for baseline and turbo-discharged engines using a relatively large turbocharger 
The torque benefit at low engine speeds can be seen to relate closely with the boost pressure shown in Figure 11. For both the larger and smaller turbochargers the achieved boost pressures below $3000 \mathrm{rpm}$ are higher with turbo-discharging than the standard engine with the same turbocharger as a direct response to the reduced turbine outlet pressure. As seen in the torque curves, the boost pressure with turbodischarging crosses that of the standard engine around $3000 \mathrm{rpm}$.

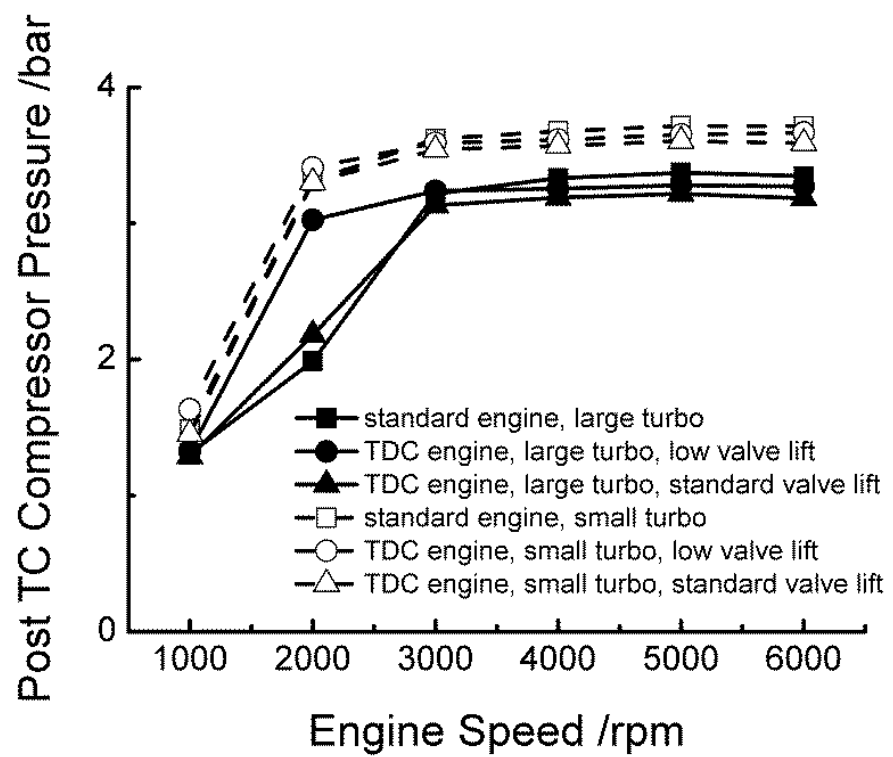

Figure 11 Effect of valve events and turbo-discharging on intake manifold (boost) pressures.

The clearest secondary effect is that of the residual fraction at part load, shown in Figure 12. At 1000 rpm hot trapped residual fraction is reduced by $>30 \%$ by the addition of turbo-discharging allowing more fresh charge into the cylinder for a given 
boost pressure and, thereby, increasing the energy available to both exhaust turbines. At higher engine speeds the residual fraction is higher in the case of the lower valve lifts indicating the restricted breathing effect of the reduced valve duration and lift; however, with the standard engine valve lifts the residual fraction is consistently reduced by $3-10 \%$ across the entire speed range (at full load) owing to the reduced exhaust manifold pressure around exhaust valve closing.

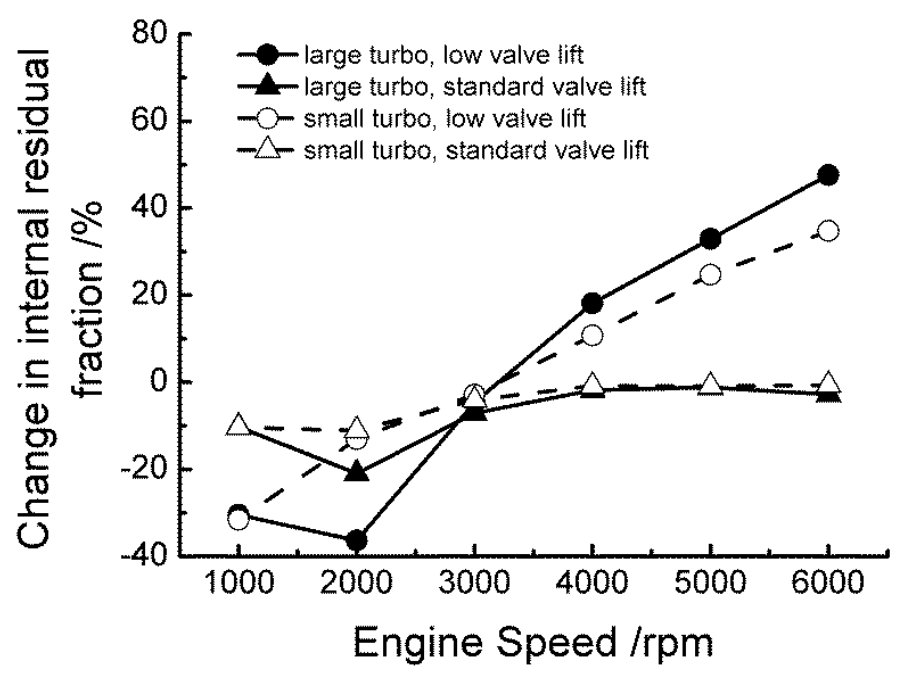

Figure 12 Effect of turbo-discharging on full load in-cylinder trapped residuals

The effect of turbo-discharging and valve timings on pumping work, shown in Figure 13, is not as definitive and is strongly linked with tuning effects of the exhaust system. The PMEP tends to be best with the standard valve timings and turbo-discharging, however, 
the effect is small in comparison to the effect on residual fraction and boost pressure. As anticipated, the pumping work for the smaller turbocharger (effectively a more narrow restriction) is noticeably higher in all cases when compared to the larger turbocharger.

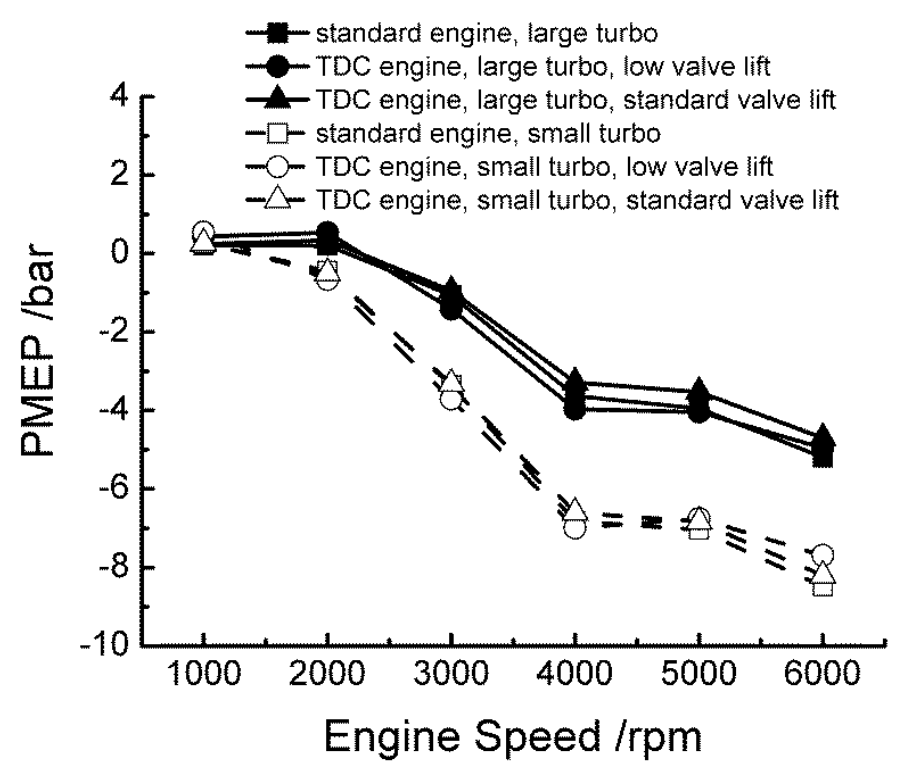

Figure 13 Effect of turbo-discharging on full load pumping mean effective pressure (PMEP)

The desire to operate turbo-discharging with standard valve timings is somewhat counterintuitive when considering the idealised operation of the system described earlier. The pressure loss across the valves is a function of the flow rate through the valves which itself is a function of the pressure ratio across the valves and the downstream flow resistance. Below the choking pressure ratio across the valves, the turbo- 
discharging flow path has an additional turbine resulting in an increased flow resistance and thereby a reduced flow rate and a higher upstream pressure than that in the low pressure manifold. When choking occurs across the valves, the high pressure manifold fills quicker than the low pressure manifold due to the presence of the additional turbine. Both of these cases result in a pressure differential between the high and low pressure manifold. Therefore, with standard valve timings and high flows (i.e. when valve flow restriction is more significant) the turbo-discharging system is capable of discharging the exhaust despite the apparent loss of the temporal isolation of the blowdown pulsation between the manifolds.

The effect of by-passing the turbo-discharging turbine and reverting to standard valve lifts will result in a turbocharging system operating in isolation thereby minimising high speed torque detriment. The main difference between the standard engine setup and such an engine would be the manifold volume upstream of the turbocharging turbine. The effect would be a marginal reduction in low-speed engine torque due to the slower pressure charging rate of the manifold and, therefore, increased valve losses.

At part load operation, one of the main aims of turbo-discharging can be to reduce the fuel consumption. Figure 14 and Figure 15 show the fuel consumption for the baseline and turbo-discharged engines with the small and large turbochargers respectively. It can be seen that the effect on fuel economy is significant, particularly at low speeds and relatively light loads ( $-25 \%$ of peak load) where more than a $4 \%$ fuel economy benefit was predicted. At lower loads the blowdown pulse reduces in magnitude 
meaning less energy is available to the turbo-discharging system and the fuel economy gain reduces. At higher speeds the turbo-discharging offers reduced pumping losses and improved fuel economy by significantly more than the $4 \%$ at part load.

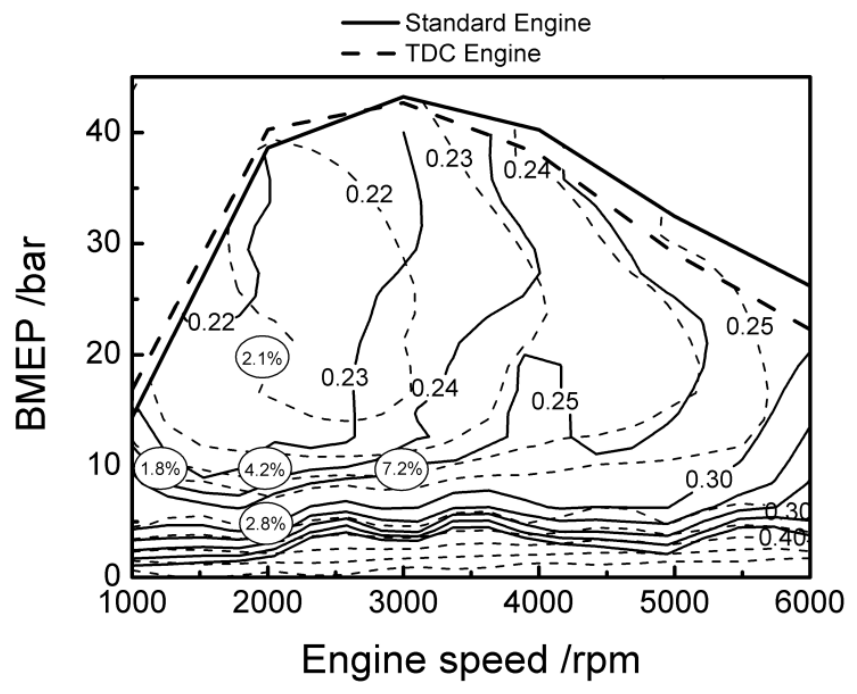

Figure 14 Comparison of BSFC for the small turbocharger $\left(\mathrm{kg} \mathrm{kWh}^{-1}\right)$. The numbers in circles represent the fuel economy advantage of the turbo-discharging system (\%) compared to the baseline.

The larger turbocharger, however, offers improved baseline engine breathing at higher engine speeds. The results shown in Figure 15 show that fuel economy across most of the engine map is improved. Below $2000 \mathrm{rpm}$ the benefit is negligible until higher loads are reached, however, at higher speeds the benefit is in excess of $4 \%$. A fuel economy detriment is observed only at speeds above $3000 \mathrm{rpm}$ and close to peak engine load. 
This is indicative of the onset of significant effects of the reduced valve lift that also manifests itself in the reduced peak engine torque under these conditions. This is the location that is expected to require switching to more conventional valve timings to achieve comparable or better engine performance. At most other conditions, the single valve timings used for this study demonstrate improvement which could be enhanced with the implementation of variable valve timing or variable valve actuation systems.

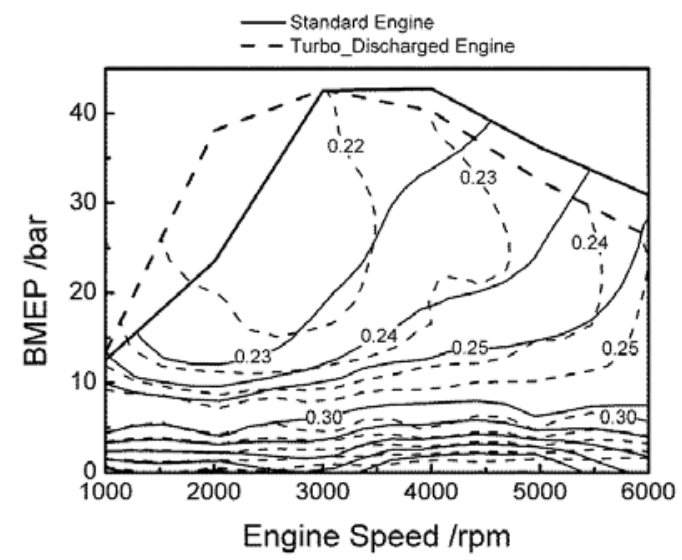

Figure 15 Comparison of BSFC for the relatively large turbocharger $\left(\mathrm{kg} \mathrm{kWh}^{-1}\right)$

The fuel economy benefit shown in Figure 14 and Figure 15 was due to the reductions in pumping work associated with lower exhaust manifold pressures during the displacement stroke when comparing the use of available exhaust energy in either the intake system or exhaust system. This is one extreme of the possible comparison strategies with the other extreme being that of a baseline with minimum boost under all conditions. This would act to reduce the pumping work on the turbo-charged baseline 
case and demonstrate a lower limit to the predicted benefit of turbo-discharging. Figure 16 shows the comparison of fuel economy benefit based on the two baseline cases indicating an upper and lower bound for the potential benefit of turbo-discharging. The fuel economy benefit of turbo-discharging with a minimum boost baseline strategy is typically between 1 and $2 \%$ and covers a wide range of the engine operating map. At lower loads, as predicted in all simulations, the fuel economy benefit reduces. Importantly, in both baseline cases, fuel economy benefit is demonstrated under both low/no boost conditions and under boosted conditions (quantified here at 20 bar BMEP).

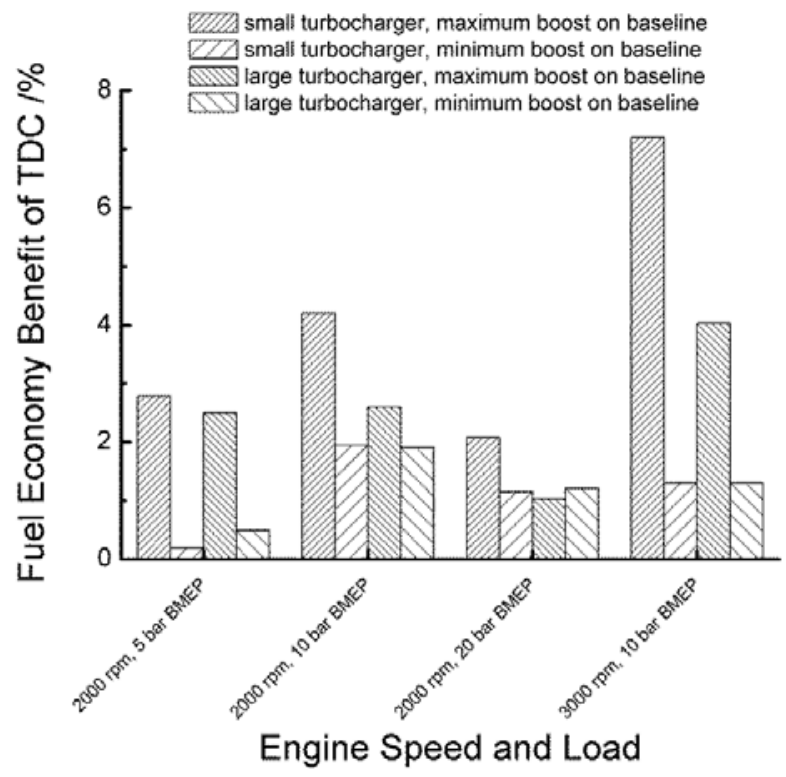

Figure 16 Comparison of fuel economy benefit of turbo-discharging based on different turbocharger sizes and baseline turbocharger part load bypass strategy 
The tendency of turbo-discharging to reduce the hot trapped residual fraction with the earlier comparison is shown in Figure 17 and Figure 18 for the small and large turbochargers respectively. This effect will tend to support emission efforts and avoid SI engine knock with residual fraction reductions of up to $60 \%$ at low speeds. Such reductions in residual fraction also result in increased throttling to control the amount of fresh charge and achieve the demand MEP. However, reduced residual fraction is expected to extend the engine's knock limit and potentially allow additional spark advance and/or compression ratio increase. To help understand these potential secondary benefits the simulation was used to predict the sensitivity of the setup to variations in spark timing and compression ratio. Compression ratio increases of 0.5 and spark advance of 5 degrees crank had the potential to improve fuel economy by $\sim 1 \%$ at part load conditions (8 bar BMEP, $2000 \mathrm{rpm}$ ) beyond those due to pumping work improvements. High loads above $3000 \mathrm{rpm}$ showed increased hot residuals due to the low lift valve events. More optimised valve timings under these conditions would be closer to the original engine valve events. 


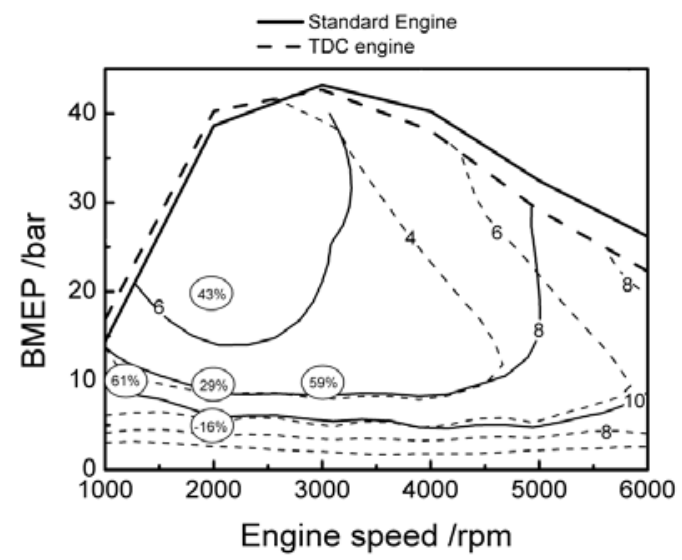

Figure 17 Comparison of trapped residual fraction for the small turbocharger (\%).

Circled values represent the reduction in residual fraction (\%) at that point.

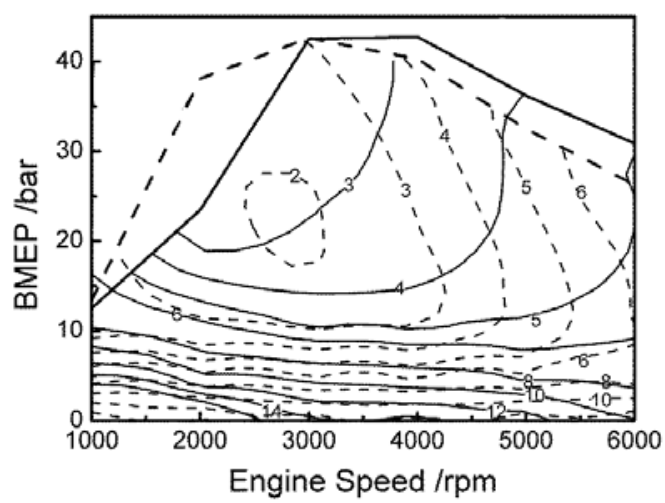

Figure 18 Comparison of trapped residual fraction for the relatively large turbocharger

The engine's transient response is an important consideration in air system design and much effort by the industry has been put towards minimising air system inertia. During 
turbo-discharging operation under no/low boost conditions the energy is recovered and used to depressurise the exhaust system. As a full load demand transient could result in bypassing the turbo-discharger the turbocharging system will (for a short time) have a significantly lower turbine outlet pressure and therefore significantly higher instantaneous power extraction. The transient response potential of a turbo-discharged turbocharged engine is therefore unique and will be evaluated in more detail in future studies once optimum turbocharger sizing and exhaust system geometry have been more clearly defined.

Although the work presented here has focused on a separate turbocharger and turbodischarger the concept of using turbine extracted energy to depressurise the exhaust in addition to pressurising the intake can be applied more widely. For example, incorporation of electric machines to the turbo system ${ }^{[12]}$ will enable effective energy flow control. The potential also exists to operate the discharger directly from crankshaft work, however, the conversion efficiency of useful fuel energy to useful compressor work is significantly lower than that of the turbo-discharging system investigated here. In addition, a large fraction of the energy recovered by turbo-discharging is normally waste energy whereas crankshaft driven work can be considered normally useful work.

\section{Synergous Technologies}

The optimum fraction of the energy to each turbine varies depending on the engine condition and overall objective. Table 2 summarises the key potential benefits of turbo- 
discharging and the optimum approach as a function of engine speed and load. The possible objectives are considered to be one or more of the following:

1. Reduced residual fraction: The hot trapped residual fraction is strongly dependent on the cylinder pressure at exhaust valve closing and, therefore, the exhaust manifold pressure. At low speeds and low loads this relationship dominates and significant reductions in residual fraction can be achieved by maximising turbo-discharger depressurisation. This in turn is achieved by maximising turbo-discharger turbine flow with the low valve lift strategies, while maintaining enough boost for engine torque and transient response requirements. At high speeds, however, the valve restriction represents a significant pressure loss in the system and if a low lift valve strategy is used, results in increased in-cylinder pressures and an increase in hot residual fraction. Under these conditions the ideal valve lift would be longer duration and higher lift, yet still benefiting from maximum levels of depressurisation due to the effects previously discussed. When boost is required, the energy flow split between the turbo machines can be controlled using conventional technologies such as by-passing, wastegating or variable geometry turbines.

2. Full load torque: When the primary objective is to achieve full load torque the strategy should vary between low and high speeds. At low speeds the benefit of turbo-discharging is significant and the energy flow should be balanced to achieve maximum boost by varying both inlet and outlet turbocharger turbine pressures. At high speeds, longer valve events are required to deliver the flow 
effectively from the cylinder to the exhaust system which with further optimisation through wastegating or variable geometry turbines should be capable of delivering higher low speed torque and comparable high speed torque to a more conventional engine.

3. Engine fuel economy: Optimisation of engine fuel economy can be separated into two main categories. Reducing part load fuel consumption for passenger car applications requires the maximum energy flow to the turbo-discharging system while maintaining engine torque. The results presented consider a single set of exhaust valve timings aimed at achieving part load fuel economy at 8 bar BMEP. Variable valve actuation will allow optimisation across a much wider range of the engine load map. At full load, engine fuel economy optimisation is a more complex balance of turbocharger and turbo-discharger energy flows, typically using maximum turbo-discharger flow with minimum boost for the required engine load. 


\begin{tabular}{|c|c|c|c|}
\hline Aim: & Condition: & Valve strategy: & $\begin{array}{l}\text { Main turbo-system } \\
\text { energy flow: }\end{array}$ \\
\hline \multirow{3}{*}{$\begin{array}{l}\text { Reduced residual } \\
\text { fraction }\end{array}$} & Part load & Low valve lift & $\begin{array}{l}\text { Maximum turbo- } \\
\text { discharger flow }\end{array}$ \\
\hline & $\begin{array}{l}\text { High load, low } \\
\text { speed }\end{array}$ & Low valve lift & $\begin{array}{l}\text { Potentially partial } \\
\text { bypass of turbo- } \\
\text { discharger (or } \\
\text { partially open VGT) }\end{array}$ \\
\hline & $\begin{array}{l}\text { High load, high } \\
\text { speed }\end{array}$ & High valve lift & $\begin{array}{l}\text { Potentially partial } \\
\text { bypass of turbo- } \\
\text { discharger (or } \\
\text { partially open VGT) }\end{array}$ \\
\hline \multirow[t]{2}{*}{ Full load torque } & Low speed & Low valve lift & $\begin{array}{l}\text { Potentially partial } \\
\text { bypass of turbo- } \\
\text { discharger (or } \\
\text { partially open VGT) }\end{array}$ \\
\hline & High speed & High valve lift & $\begin{array}{l}\text { Full turbo- } \\
\text { discharger bypass } \\
\text { (or open VGT) }\end{array}$ \\
\hline \multirow[b]{2}{*}{ Fuel economy } & Part load & Low valve lift & $\begin{array}{l}\text { Maximum turbo- } \\
\text { discharger flow }\end{array}$ \\
\hline & High load & $\begin{array}{l}\text { Subject to } \\
\text { turbocharger size } \\
\text { and engine speed }\end{array}$ & $\begin{array}{l}\text { Maximum turbo- } \\
\text { discharger flow }\end{array}$ \\
\hline
\end{tabular}

Turbo-discharging has been explored previously in isolation as a technology that can significantly improve engine fuel economy and torque when applied to NA IC engines. In combination with downsized turbocharged engines it is apparent that optimum operation of the whole system will benefit from synergous technologies. In particular, the use of air flow control methods including variable valve actuation (e.g. cam profile switching, 'cam-in-cam, [13] or variable exhaust valve timing) and turbine technologies such as VGT and wastegating. VVA and VGTs in particular will give scope for optimisation of whole system performance beyond that presented. Of particular interest 
is the effect of turbo-discharging on low speed torque with (relatively) larger turbochargers shown in Figure 10. The simulation results suggest that a single turbocharger in conjunction with a single turbo-discharger is capable of achieving comparable engine low speed torque as that of a twin turbocharger arrangement. However, it also offers the additional benefits of reduced residual fraction and improved fuel economy. The implementation of turbo-discharging on heavily boosted downsized gasoline engines may not, therefore, require an additional turbomachine, but instead, replacing one of the turbochargers with a turbo-discharger.

\section{$\underline{5 .}$ Conclusions}

Turbo-discharging is a new and unique approach to improving the fuel economy and performance if IC engines. It has previously been analysed in the context of naturally aspirated gasoline engines and is expected to be of particular value to the automotive gasoline engine market and the power generation market. The trend of engine boosting and downsizing means that the interaction between turbo-discharging and the turbocharging system is important. This paper has, therefore, applied one-dimensional gas dynamic engine simulations to understand the effects of turbo-discharging a turbocharged gasoline engine with a particular emphasis on peak torque and fuel economy. Combustion timing and limits were fixed so that boundaries of operation could be identified for future, less constrained combustion systems. The analysis shows that: 
1. Turbo-discharging increased engine low speed torque due to increased boost by way of lower turbocharger turbine outlet pressure. This was very evident at 2000rpm with the larger turbocharger which achieved boost levels similar to that of the smaller turbocharger;

2. For a fixed 'low lift' valve timing optimised for part load fuel economy, peak torque at high engine speeds (>3000 rpm) was reduced;

3. The use of more conventional exhaust cam profiles at high speeds and loads still generated a discharging effect and peak engine torques were more similar to that of the turbocharged engine;

4. Turbo-discharging demonstrated consistently part load fuel economy benefits. The magnitude of the improvement was typically between 2 and $7 \%$ depending on the baseline engine air system control strategy.

5. The primary fuel economy benefit was due to improved engine breathing and reduced pumping work.

6. There was a significant reduction in hot trapped residual mass which could contribute to additional benefits by extending the knock limit of gasoline engines.

A discussion of the potential synergous technologies and control approaches suggests that variable valve actuation and conventional turbocharger control mechanisms (waste-gating and VGT) would improve the performance of the turbocharged, turbodischarged engines. The results of this study are extremely positive and support the case for further exploration of turbo-discharging as an additional dimension to the air 
system energy flow architecture for optimisation of both fuel economy and combustion performance through hot trapped residual fraction.

\section{$\underline{\text { Acknowledgements }}$}

The authors would like to acknowledge the support of the Engineering and Physical Sciences Research Council (EPSRC) and Technology Strategy Board (TSB) as part of the Low Carbon Vehicles Integrated Delivery Programme (Grant EP/H050353/1); and the Royal Academy of Engineering.

\section{References}

[1] D. Mignard and C. Pritchard. Processes for the Synthesis of Liquid Fuels from CO2 and Marine Energy. Transactions of the Institution of Chemical Engineers Vol 84 (A9) pp828-836, 2006.

[2] Foresight Vehicle for the Department of Trade and Industry. Foresight Vehicle Technology Roadmap: Technology and Research Directions for Future Road Vehicles", Version 3.0, 2008.

[3] E. Hellström, M. Ivarsson, J. Åslund, L. Nielsen. Look-ahead control for heavy trucks to minimise trip time and fuel consumption. Control Engineering Practice vol 17 pp245-254, 2009. 
[4] H. Khayyam, A.Z. Kouzani, E.J. Hu, S. Nahavandi. Coordinated energy management of cehicle air conditioning system. Applied Thermal Engineering, Vol 31 pp750-764, 2011.

[5] H. Blaxill, S. Reader, S. Mackay, B. Lerch, J. Rueckauf. Development of a Friction Otimized Engine. SAE Technical Papers, Paper 2009-01-1052, 2009.

[6] K.D. Edwards, R. Wagner and T. Briggs. Investigating Potential Light-duty Efficiency Improvements through Simulation of Turbo-compounding and Waste-heat Recovery Systems. SAE Technical Papers, Paper 2010-01-2209, 2010.

[7] A.M. Williams, A.T. Baker, C.P. Garner. Turbo-Discharging: Predicted Improvements in Engine Fuel Economy and Performance. SAE Technical Papers, Paper 2011-01-0371, 2011.

[8] C.E. Möller, P. Johansson, B. Grandin, F. Lindström. Divided Exhaust Period - A Gas Exchange System for Turbocharged SI Engines. SAE Technical Papers, Paper 2005-01-1150, 2005.

[9] W. Shouren, G. Peiquan, Y. Liying. Centrifugal precision case TiAl turbocharger wheel using ceramic mould. Journal of Material Processing Technology Vol 204 pp492497, 2008.

[10] S. Rajoo, R.F. Martinez-Botas. Improving Energy Extraction from Pulsating Exhaust Flow by Active Operation of a Turbocharger Turbine. SAE Technical Papers, Paper 2007-01-1557, 2007. 
[11] G. Lumsden, D. OudeNijeweme, N. Fraser, H. Blaxill. Development of a Turbocharged Direct Injection Downsizing Demonstrator Engine. SAE Technical Papers, Paper 2009-01-1503, 2009.

[12] W. Zhuge, L. Huang, W. Wei, Y. Zhang, Y. He. Optimization of an Electric Turbo Compounding System for Gasoline Engine Exhaust Energy Recovery. SAE Technical Papers, Paper 2011-01-0377, 2011.

[13] J. Taylor, N. Fraser, R. Dingelstadt and H. Hoffmann. Benefits of Late Inlet Valve Timing Strategies Afforded Through the Use of Intake Cam In Cam Applied to a Gasoline Turbocharged Downsized Engine. SAE Technical Papers, Paper 2011-010360, 2011. 


\section{List of Captions}

Figure 1. Idealised P-v diagram showing (a) 'normally wasted' energy recoverable by a turbine and (b) additional crankshaft work available to the turbine

Figure 2. Schematic of air flow pathways for turbocharging, turbocompounding and turbo-discharging systems in isolation

Figure 3. Schematic of a turbo-discharged turbocharged IC engine air system. $\mathrm{Q}_{\mathrm{IC}}$ is the heat removed by the intercooler and $\mathrm{Q}_{\text {optional }}$ is the heat rejected from the exhaust system.

Figure 4. Relationship between valve event duration and maximum lift

Figure 5. Example low lift valve timings used for simulations

Figure 6 Cylinder pressure and exhaust manifold pressures for part load operation (8 bar BMEP, 2000 rpm)

Figure 7 Cylinder pressure, exhaust manifold pressures and post turbocharger turbine pressure for full load operation (2000 rpm)

Figure 8 Instantaneous mass flux into the exhaust manifolds from cylinder 1 for part load and full load operation (2000 rpm)

Figure 9 Engine torque curve for baseline and turbo-discharged engines using a small turbocharger 
Figure 10 Engine torque curve for baseline and turbo-discharged engines using a relatively large turbocharger

Figure 11 Effect of valve events and turbo-discharging on intake manifold (boost) pressures.

Figure 12 Effect of turbo-discharging on full load in-cylinder trapped residuals

Figure 13 Effect of turbo-discharging on full load pumping mean effective pressure (PMEP)

Figure 14 Comparison of BSFC for the small turbocharger $\left(\mathrm{kg} \mathrm{kWh}^{-1}\right)$. The numbers in circles represent the fuel economy advantage of the turbo-discharging system (\%) compared to the baseline.

Figure 15 Comparison of BSFC for the relatively large turbocharger $\left(\mathrm{kg} \mathrm{kWh}^{-1}\right)$

Figure 16 Comparison of fuel economy benefit of turbo-discharging based on different turbocharger sizes and baseline turbocharger part load bypass strategy

Figure 17 Comparison of trapped residual fraction for the small turbocharger (\%).

Circled values represent the reduction in residual fraction (\%) at that point.

Figure 18 Comparison of trapped residual fraction for the relatively large turbocharger 